\title{
Enhancing Decision Making Skills among Postgraduate Students Using Alternative Assessment Approach
}

\author{
Marini Kasim*, Mohd Faiz Mohd Yaakob, Faizahani Ab Rahman \\ School of Education and Modern Languages, Universiti Utara Malaysia, Malaysia
}

Received April 22, 2020; Revised September 3, 2020; Accepted September 17, 2020

\section{Cite This Paper in the following Citation Styles}

(a): [1] Marini Kasim, Mohd Faiz Mohd Yaakob, Faizahani Ab Rahman , "Enhancing Decision Making Skills among Postgraduate Students Using Alternative Assessment Approach," Universal Journal of Educational Research, Vol. 8, No. 11, pp. 5670 - 5675, 2020. DOI: 10.13189/ujer.2020.081171.

(b): Marini Kasim, Mohd Faiz Mohd Yaakob, Faizahani Ab Rahman (2020). Enhancing Decision Making Skills among Postgraduate Students Using Alternative Assessment Approach. Universal Journal of Educational Research, 8(11), 5670 - 5675. DOI: 10.13189/ujer.2020.081171.

Copyright $\odot 2020$ by authors, all rights reserved. Authors agree that this article remains permanently open access under the terms of the Creative Commons Attribution License 4.0 International License

\begin{abstract}
Postgraduate learning in Malaysian public or private universities has undergone tremendous shift in its landscape that a continuous diversity of trends has emerged where postgraduate programmes are now offered to a large number of local and foreign postgraduate students. One of the expected aspects of being postgraduates means having to make decisions that are not only wise, but also sound and apt. This requires postgraduates to acquire high level and value decision making skills that would prevent them from making catastrophic decisions such as choosing the right subject matter to investigate, supervisors and appropriate research instruments. Thus, the purpose of this study is to enhance the level of decision-making skills among master students in Strategic Management course using alternative assessment. Using explorative qualitative approach, this study employed an action research where participants' decision-making skills were evaluated followed by intervention treatments that would help them to make better decisions. Ten postgraduate students were asked to complete a self-filled questionnaire and participated in focus group discussion in the first phase of the data collection. SWOT analysis and presentation rubric were used as intervention tools in this study. Results indicated an increase of score from $79 \%$ to $85 \%$ at the end of the assessment. This concludes that the alternative assessment helps students to make better decisions. The findings illustrated that alternative assessment is different from the restrictive forms of traditional assessment and is advantageous to students, stakeholders, employers, funding bodies and others as it helps to establish
\end{abstract}

capabilities and competencies as well as academic knowledge.

Keywords Alternative Assessment, Scholarship Teaching and Learning, Decision-making Skills, Problem-solving Skills

\section{Introduction}

Global education requires educators to explore various methods to improve learning outcomes continuously. This study aims to examine the feasibility of implementing alternative assessments to enhance decision-making skills in educational organizations for students pursuing a course in Strategic Management in Education. This is a compulsory course for postgraduate students pursuing Master of Science, specializing in Educational Management at Universiti Utara Malaysia (UUM). The objective of this programme is to develop and enhance students' ability and skills in school's management. Based on the Course Learning Outcomes (CLO), after partaking this course, these in-service and prospective school administrators should be able to apply appropriate decision-making skills in the actual environment of the respective educational organizations. Accordingly, students' ability to master problem-solving skills in a real-world environment would ensure that other related CLOs are achievable as well. 
Based on the observations and evaluations of researchers who have taught this course for three semesters, it is concluded that most students were unable to relate and apply the learned theories and concepts to their actual situation at schools, either as administrators or general educators. Thus, this simply illustrates that on a practical basis, decision-making skills are vital for these students' careers as they hold significant positions in their respective organizations. Therefore, decision-making skills play a crucial role in shaping these postgraduates and educational organizations.

\section{Literature Review}

\subsection{Decision Making Skills}

For all organizations, there are decisions that must be made and for each level of the organization. The decision-making process ranges from strategic management decisions for the entire organization to the day-to day operations. The decision-making process in an educational organization is similar to any other business organizations since both aim to achieve a certain set of goals. In addition, emotions play an important role in the decision-making process [1]. Nevertheless, effective decision-making is not just making choices but it also involves the process of identifying problems, listing and selecting alternatives, implementing alternatives and solutions, and evaluating to know which alternative is the best and has the highest chances of success. Organizations that have the vision of becoming successful and staying ahead of others are those that have a strong line of administrators with excellent critical thinking and decision-making skills [2]. Changes would be difficult if organizations overlooked the importance of these thinkers (i.e. administrators) within their organizations.

Meanwhile, critical thinking is reflection using reasonable justifications and perceptions of our beliefs [3]. This serves as a guide for an individual to act effectively and aptly and to make appropriate decisions in a given situation [3]. Critical thinking is also portrayed as a practical skill, yet at the same time, it is a careful strategic structure and planning as well as extensive involvement in testing not only one's own thinking but the thinking of others. On the other hand, decision-making skill is a mental process that leads to some actions being made consciously or unconsciously [4]. It involves critical thinking since it is highly required during the decision-making process.

\subsection{Alternative Assessment}

Alternative assessment, also referred as authentic assessment, includes all sorts of assessments that are used to measure students' capability in undertaking complex tasks that are related to the learning outcomes. Some examples of alternative assessments are students' portfolios, project work, problem-based assessment, portfolio assessment and technology-based assessment. In the context of this study, performance-based assessment (PBA) is used as one of the assessment tools in alternative assessment. It is a form of assessment that deviates from the traditional paper-and- pencil assessment. As PBA is closely related to the context that mimics the workplace, it is chosen specifically in here where students taking this particular course are expected to complete the assigned tasks using their working experience and knowledge.

The alternative assessment introduced in this study uses a performance-based assessment (PBA) technique, an assessment that does not use pencil-paper-based traditional assessment method. Instead, PBA is a task assigned to students based on the actual circumstances or issues in a particular school environment or educational organization. The assigned tasks are expected to extract specific knowledge, skills, and characteristics among the students. In the context of this study, the students are expected to extract specific knowledge and skills and apply them in their tasks.

The assessment was designed in accordance with the Programme Educational Objectives (PEO), Programme Learning Outcomes (PLO) and Course Learning Outcomes (CLO) set for the course Strategic Management in Education, adhering to Malaysian MQA requirement.

Alternative assessment is introduced not only to assess students' knowledge but also to evaluate their ability to apply knowledge. Alternative assessment consists of multiple dimensions that look at students' learning process through the lens of behavioral changes within real contexts. This method of assessment is criterion-based, and one of the measurement tools used is rubric [5]-[8]. [9] stated that alternative assessment is an authentic indicator for measuring students' application of knowledge and skills. It also enhances students' skills through projects, portfolios, and activities. This method of assessment is also said to be more comprehensive since it is based on clearly defined tasks that the students need to perform in his/her own workplace (authentic) [9].

PBA has many benefits for students and lecturers [15] [16]. These include:

1) Learned knowledge of decision-making skills which can be applied in real-life contexts and environments.

2) knowledge that would be applied once students learnt to think, analyze, innovate, and, develop their talents to think creatively and critically.

3) communication skills, especially during the presentation session that will be improved as students learn to clearly explain to the assessor the justification for all actions taken during the decision-making process.

As such, an assessment such as PBA is more realistic, as it increases knowledge and understanding. Since skills and knowledge are simultaneously measured, the 
assessment will produce more accurate and comprehensive results. Moreover, it provides ample space and opportunities for lecturers to understand effective teaching methods better (in this case, in the form of reflection) [18]. Meanwhile, through alternative assessment, students are given the same opportunity to apply the knowledge gained to the best of their ability. This type of assessment could also motivate students to become autonomous learners.

Alternative assessment is not limited to content knowledge; it also assesses knowledge and skills related to capacity building [5]. In addition, alternative assessment also reflects behavior as a result of the learning process [10] and evaluates high-level thinking skills [11]. Alternative assessment is not only used in face-to-face learning but has reportedly been used in blended and online learning [9].

The purpose of the assessment also changes from the traditionally assessing the level of knowledge that the students could acquire to assessing students' ability to apply what they have learned [12]. In addition, alternative assessment also examines the development of students' values, attitudes, and behaviors in both inside and outside the classroom through various assessment methods [13]. As a result of the transition of assessment to meet current needs, new approaches need to be considered for measuring the performance of 21st-century students. Among the principles to be considered in implementing the PBA are [15],[16]:

1) Assignments given to students involve assessment of high-level thinking skills across three learning domains, namely cognitive, affective, and psychomotor.

2) Authentic; assessment is made based on the actual issues or problems that occur in the educational organizations.

3) Parallel (aligned); the assessment is made per the predefined Course Learning Outcome. A clear rubric is essential to guide the assessor/lecturer in assessing students' performance. Students should also be aware of the assessed criteria.

\section{Methodology}

In this study, qualitative approach was chosen to examine the feasibility of implementing alternative assessments to enhance decision making skills among postgraduate students. Here, focus group discussions and semi structured interviews were used. During the focus group interview, all responses were treated with the following procedures:

i). Using protocols: Data recording protocols are designed and used by qualitative researchers to record information during interviews.

ii). Transcribing Data: Transcribing is converting speech to text word for word. Transcribing is a common practice when conducting interviews because it enables to perform analysis. Transcription is the process of converting tape recording into text dat.

iii). Analysis: In this study, researchers use thematic hand analysis. The hand analysis of qualitative data means that researchers read the data a few times, marked and categorized them according to the themes which were i) their levels of decision making and ii) understanding of SWOT analysis for problem solving.

iv). Design of qualitative action research: Action research was chosen as the research design since the researchers aimed at improving self-teaching techniques as well as improving their own understanding of the best educational practices. Action research has been shown to be suitable for studying issues in teaching [14]. This approach also enables the knowledge of teachers or lecturers to be part of the educational literature and, thus, contributes to the construction of educational structures.

Before assessment can be conducted it has to be validated by the Committee of Academic and Examination. The result analysis used percentage before and after the assessment.

The chosen ten participants for this research were those who were enrolled in the Strategic Management in Education course. There were ten participants in this study, two males and eight females. Their age ranges from 26 years old to 40 years old with a mean of 33 , as illustrated in Table 1 below:

Table 1. Demographic Profile of Respondents

\begin{tabular}{|c|l|ll|}
\hline Gender & & \multicolumn{2}{|l|}{ Ages } \\
\hline Male & 2 & $<20$ & 0 \\
\hline Female & 8 & $<30$ & 0 \\
\hline & & $<40$ & 10 mean $=33$. \\
\hline
\end{tabular}

This study was based on three phases.

\section{Phase 1}

Phase 1: Identification level of decision-making skills

In this first phase, students were asked to answer a set of questions (inventory) to determine their level of decision-making skills. The level was determined by the provided decision-making skills' rubric, adapted from Catalina Foothills School District $21^{\text {st }}$ Century Learning Rubric-Skill: Critical and Creative Thinking. [17].

In this inventory, participants were required to set their level of decision-making skills based on the items given. Once they completed the questionnaire, they would be informed of their levels of decision making. Next, focus group discussions were conducted where the students' decision-making skills were explored, determined, analyzed and factors that lead them to making certain 
decisions were also established. Both questionnaire and focus group discussions were compared to SWOT analysis and presentation rubric before participants level of decision making and factors leading them to making decisions could be compared.

\section{Phase 2:}

\section{Intervention 1 (SWOT Analysis)}

The second phase was the initial phase of the intervention which was introduction to decision-making skills. During this phase, students were introduced to the decision-making skills through a series of SWOT analysis procedures. Firstly, students were briefed and explained on what constitutes SWOT analysis before they were guided on the process using strengths, weaknesses, opportunities, and threats components in the analysis. Next, students were asked to apply decision-making skills to solve the actual problems and issues that were taking place in their respective organizations. The SWOT analysis matrix was used by the students as the basic guidelines for problem-solving process and this subsequently led them to make appropriate decisions. Then, assessment was made on the level of students' decision-making skills based on their own SWOT analysis matrix. During this phase, students were asked to prepare reflective reports on their decision-making and problem-solving skills so as to determine their level of decision-making and problem-solving skills.

Intervention 2 (Alternative Assessment)

The second intervention was conducted to enhance the impact of alternative assessment on decision-making skills among postgraduate students. This intervention was intended to improve students' understanding of decision-making skills and subsequently solve their identified problems in particular organizations. Additionally, presentation sessions and group discussions on decision making and problem-solving were conducted. Apart from that, students reflective writing was also assessed using scoring rubric. Next, students' SWOT analysis matrixes generated by the students were assessed before further assessments were made on their level of decision-making skills.

\section{Phase 3:}

The third and final phase was evaluation phase in which the researchers evaluated the students' presentations to identify if they have improved their decision-making and problem-solving skills. During this evaluation process, students were required to present one of their tasks which was the findings on the problem or issue that they have successfully resolved. The overall scorings of the presentations were the final process of this action research.

\section{Findings and Discussions}

The result for each phase was analyzed, and the findings were presented as follows.

\section{Phase 1: Participants' level of decision-making skills}

At the beginning, students were asked to answer a set of questions to determine and measure the level of decision-making based on the Catalina rubric. The result of the total rubrics was at the level (67.5\% -81.7\%), which was equivalent to moderate level. In addition, data from semi structured focus group discussion illustrated the diversity of responses to decision-making skills as stated by R1; R2; R4; and R5 respectively:

R1-ask someone; R2-depends on the situation

R4-ask for opinion;

R5-i will change, but [will] consider the cause and effect

Meanwhile, R3 indicated that she has a clear stand on their decisions, as stated in the following statement.

R3- usually does not change

On the other hand, R6 demonstrated flexibility when making important decisions. This proved that the respondent has good judgment on the situation in her decision-making skills. This is displayed as follows:

\section{R6-I am flexible based on the circumstances}

The overall findings from phase one showed that students were at a moderate level and were still confused or unclear and unsure about their decision-making skills in their lives and work environment.

\section{Phase 2: Intervention 1 (Introduction to SWOT Analysis)}

During this phase, the intervention was conducted on students through the following four situations; i) Students were first introduced to decision-making skills, ii) Students /lecturer determined the organizations that needed to be studied, iii) Students set real issues to be studied and apply decision-making skills, and iv) Students apply SWOT analysis matrix.

Next, a matrix of the SWOT analysis was generated by the students and subsequently, this SWOT analysis was introduced as a tool for improving decision-making skills, where a rubric was built to measure self-reflection ability.

Observations were also conducted using observation checklist to evaluate the process of completing the assigned tasks among students. The following was findings of the participants' SWOT analysis:

R1: SWOT sequences were not structured

R2: SWOT analysis not clear

R3: SWOT lack accuracy

R4: Lack of structure

R6: Unsatisfactory 


\section{R7: Satisfactory but unstructured}

Meanwhile, only four students showed satisfactory understanding of the SWOT analysis (R5, R8, R9 and R10).

Most students scored moderately in their reflections, ranging from $70-90 \%$, illustrating/proving that students might have general ideas on SWOT analysis.

The overall reflection scores are shown in Table 2:

Table 2. Reflective Writing Scoring Rubrics of Intervention 1

\begin{tabular}{|c|c|c|}
\hline Respondent & Scores & Percentage \\
\hline R1 & 8 & $80 \%$ \\
\hline R2 & 9 & $90 \%$ \\
\hline R3 & 8 & $80 \%$ \\
\hline R4 & 7 & $70 \%$ \\
\hline R5 & 8 & $80 \%$ \\
\hline R6 & 7 & $70 \%$ \\
\hline R7 & 7 & $70 \%$ \\
\hline R8 & 9 & $90 \%$ \\
\hline R9 & 9 & $90 \%$ \\
\hline R10 & 7 & $70 \%$ \\
\hline Overall & 79 & $79 \%$ \\
\hline
\end{tabular}

\section{Phase 2: Intervention 2 (SWOT Analysis)}

After discovering that the overall students' rubric score was at the moderate level (79\%), the researcher conducted alternative assessments by asking students to:

i). choose an issue they wish to resolve in their organization,

ii). use SWOT analysis to solve the identified issue or problem in their organization,

iii). write reflective writing using the given scoring rubrics.

As a result of the alternative assessments conducted, the researchers found an increment from $79 \%$ to $85 \%$. The overall rubric of students' reflective writing is presented in Table 3.

Table 3. Reflective Writing Scoring (Alternative Assessment) section of intervention 2

\begin{tabular}{|c|c|c|}
\hline Respondent & Scores & Percentage \\
\hline R1 & 9 & $90 \%$ \\
\hline R2 & 9 & $90 \%$ \\
\hline R3 & 9 & $90 \%$ \\
\hline R4 & 9 & $90 \%$ \\
\hline R5 & 9 & $90 \%$ \\
\hline R6 & 7 & $70 \%$ \\
\hline R7 & 8 & $80 \%$ \\
\hline R8 & 9 & $90 \%$ \\
\hline R9 & 9 & $90 \%$ \\
\hline R10 & 7 & $70 \%$ \\
\hline Overall & 85 & $85 \%$ \\
\hline
\end{tabular}

\section{Intervention 2: Reflective Writing Scoring Rubric as Alternative Assessment}

From the intervention, there was an increase from $79 \%$ to $85 \%$ overall score, a $6 \%$ improvement in the assessment. There were a lot more students who scored $90 \%$ in the reflective writing. The differences in the scores for each student are illustrated in Table 4.

Table 4. The difference of Increments in Students' Scores

\begin{tabular}{|c|c|c|c|}
\hline Respondent & $\begin{array}{c}\text { Reflective } \\
\text { Writing Scoring } \\
\text { Rubric 1 }\end{array}$ & $\begin{array}{c}\text { Reflective } \\
\text { Writing Scoring } \\
\text { Rubric 2 }\end{array}$ & Increase \\
\hline R1 & $80 \%$ & $90 \%$ & $10 \%$ \\
\hline R2 & $90 \%$ & $90 \%$ & $0 \%$ \\
\hline R3 & $80 \%$ & $90 \%$ & $10 \%$ \\
\hline R4 & $70 \%$ & $90 \%$ & $20 \%$ \\
\hline R5 & $80 \%$ & $90 \%$ & $10 \%$ \\
\hline R6 & $70 \%$ & $70 \%$ & $0 \%$ \\
\hline R7 & $70 \%$ & $80 \%$ & $10 \%$ \\
\hline R8 & $90 \%$ & $90 \%$ & $0 \%$ \\
\hline R9 & $90 \%$ & $90 \%$ & $0 \%$ \\
\hline R10 & $70 \%$ & $70 \%$ & $0 \%$ \\
\hline Overall & $79 \%$ & $85 \%$ & $6 \%$ \\
\hline
\end{tabular}

Six students managed to obtain $90 \%$, as compared to 3 before the introduction of the alternative assessment. In addition, there were five students who score consistently for both phases. Only one student, R10, received a static mark of $70 \%$. Student R4 scored the most significant improvement by a $20 \%$ increase. Finally, four students had a similar increase of $10 \%$.

\section{Phase 3}

In this last phase, the researchers evaluated the students' presentations to determine if they had improved their decision-making and problem-solving skills. Also, in this phase, students presented their findings on the problem or issue that they successfully resolved. The overall scoring of the presentation is the final process of this action research. Each scoring is given based on the student's presentation rubric. The overall final scores of the students showed excellent results with five students scoring A. Three students scored A-. All in all, these indicate a significant improvement in Strategic Management in Education course, illustrating a significant increase in students' decision-making skills.

\section{Conclusion}

The research concluded that the students' decision-making and problem-solving skills showed significantly improved scores. This implies that 
alternative assessment is effective and could help students to make better decisions in solving problems in their respective organizations. The two-stage intervention has also been proven to be effective in improving decision-making skills among postgraduate students. The use of alternative assessment elements based on the actual situation in their organization succeeded in enhancing the level of decision-making and problem-solving skills among postgraduate students. The SWOT analysis matrix introduced during environmental analysis throughout the study also helped to enhance decision-making skills, proving that the action research approach was appropriate as a tool to enhance classroom teaching. By the same token, the results demonstrated that the interventions had facilitated students to integrate and implement the theories and concepts in this course with their actual situations at school as administrators specifically, or educators in general.

\section{Acknowledgments}

This paper is a part of a research project entitled Enhancing Decision Making Skills among Postgraduate Students Using Alternative Assessment Approach , project reference Code SO (14514). This project is funded by Universiti Utara Malaysia with a grant from UTLC-RIMC

\section{REFERENCES}

[1] M. Jacques and G. Osman, "The Role of Gender and Education on Decision-Making,” Stud. Bus. Econ., vol. 14, no. 3, pp. 117-130, 2020.

[2] T. Bednarz, "Why Organizations Need Critical Thinkers," Contract Manag., vol. 53, pp. 14-16, 2013.

[3] R. Ennis, "An Outline of Goals for A Critical Thinking Curriculum and Its Assessment." Retrieved from http://facultyed.uiuc.edu/rhennis/outlinegoalsctcurassess3.h tm.

[4] B. R. Newell and D. R. Shanks, "Unconscious Influences on Decision Making: A Critical Review,” Behav. Brain Sci., vol. 37, no. 1, pp. 1-18, 2014, [Online]. Available: https://doi.org/10.1017/S0140525X12003214.
[5] S. Hase and C. Kenyon, "Heutagogy: A Child of Complexity Theory,” Complicity An Int. J. Complex. Educ., vol. 4, no. ', pp. 111-117, 2007.

[6] Assessment Reform Group, “Assessment for Learning: 10 Principles. Research-Based Principles to Guide Classroom Practice," 2020.http://www.hkeaa.edu.hk/DocLibrary/SBA /HKDSE/Eng_DVD/doc/Afl_principles.pdf.

[7] P. L. Maki, "Moving Beyond a National Habit in the Call for Accountability," Peer Rev. Emerg. Trends Key Debates Undergrad. Educ., vol. 11, no. 1, pp. 13-14, 2009.

[8] P. Blumberg, Assessing and Improving Your Teaching: Strategies and Rubrics for Faculty Growth and Student Learning. San Francisco, CA: Jossey-Bass: A Wiley Brand, 2014.

[9] B. S. Litchfield and J. V. Dempsey, "Alternative Assessment Techniques for Blended and Online Courses,” in IADIS International Conference on E-Learning, 2013.

[10] Educause Learning Initiative, "7 Things You Should Know About Competency-Based Education,” 2014. http://www.ed ucause.edu/library/resources/7-things-you-should-know-ab out-competency-based-education.

[11] D. R. Garrison and N. D. Vaughan, Blended Learning in Higher Education - Framework, Principles and Guidelines. San Francisco, CA: Jossey-Bass: A Wiley Brand, 2008.

[12] H. Braun, A. Kanjee, E. Bettinger, and M. Kremer, "Improving Education Through Assessment, Innovation and Evaluation,” 2006, [Online]. Available: http://www.amacad .org/publications/braun.pdf.

[13] Assessment Reform Group, "Assessment for Learning: 10 Principles," Research-Based Principles to Guide Classroom Practice, 2002. http://www.hkeaa.edu.hk/DocLibrary/SBA/ HKDSE/Eng_DVD/doc/Afl_principles.pdf.

[14] M. Cochran-Smith and S. L. Lytle, "Research on Teaching and Teacher Research: The Issues That Divide,” Educ. Res., vol. 19, no. 2, pp. 2-11, 1990.

[15] Stiggins, R. (2008). Introduction to student- involved assessment for learning (5th ed.). Upper Saddle River, NJ: Prentice Hall.

[16] Gallavan, N. P. (2009). Developing perfor- mance-based assessments, grades 6-12. Thousand Oaks, CA: Corwin.

[17] Catalina Foothills School District (2006) $21^{\text {st }}$ Century Learning Rubric-Skill: Critical and Creative Thinking.

[18] Lai, E. (2011). Performance-based Assessment: Some New Thoughts on an Old Idea. Bulletin, 20. Retrieved from http://www.pearsonassessments.com 